УДК 597.34 (28) (597)+597-152.2

И. А. Столбунов, И. В. Шляпкин

Институт биологии внутренних вод им. И. Д. Папанина РАН

\title{
СУТОЧНАЯ ДИНАМИКА ВИДОВОГО РАЗНООБРАЗИЯ И ПЛОТНОСТИ СКОПЛЕНИЙ РЫБ В ПРИБРЕЖНОЙ ЗОНЕ ВОДОХРАНИЛИЩА КАМ ЛАМ И ЕГО ПРИТОКА СУОИ КОК
}

(ВБЕТНАМ)

\begin{abstract}
Изучена суточная динамика видового разнообразия и плотности скоплений рыб в прибрежных биотопах разного типа водохранилища Кам Лам и устьевом участке его притока - р. Суои Кок (Центральный Вьетнам). В биотопах разного типа на протяжении суток происходило изменение числа видов рыб и перераспределение их долей в составе скоплений. В темное время суток видовое разнообразие прибрежных скоплений рыб возрастало.
\end{abstract}

I. А. Столбунов, І. В. Шляпкін

Інститут біології внутрішніх вод ім. І. Д. Папаніна РАН

\section{ДОБОВА ДИНАМІКА ВИДОВОГО РІЗНОМАНІТТЯ \\ ТА ЩІЛЬНОСТІ СКУПЧЕНЬ РИБ У ПРИБЕРЕЖНІЙ ЗОНІ ВОДОСХОВИЩ КАМ ЛАМ ТА ЙОГО ПРИТОКИ СУОІ КОК (B'CTHAM)}

Досліджено добову динаміку видового різноманіття та щільності скупчень риб у прибережних біотопах різного типу водосховища Кам Лам та вустя його притоки - p. Суоі Кок (Центральний В'стнам). У біотопах різного типу протягом доби відбуваються зміни кількості видів риб і перерозподіл їх часток у складі скупчень. У темний період доби видове різноманіття прибережних скупчень риб зростало.

\author{
I. A. Stolbunov, I. V. Shlyapkin \\ Institute of Biology of Inland Waters, Russian Academy of Sciences
}

\section{DAILY DYNAMICS OF SPECIES DIVERSITY AND DENSITY CLUSTERS OF FISH IN THE COASTAL ZONE OF RESERVOIR KAM LAM AND ITS TRIBUTARY SUOI COC (VIETNAM)}

The daily dynamics of fish diversity and density aggregations in different riparian habitats of the reservoir Kam Lam and its tributary mouth - the river Suoi Coc (Central Vietnam) were studied. We found the change of species number and its percentage redistribution in the aggregations over the entire circadian period in the different types of habitats. It is noted that in the night the fish species diversity of littoral aggregations increased.

\section{Введение}

Миграции относятся к важнейшим аспектам биологии многих морских, пресноводных и проходных рыб и других водных животных. Существенное место среди различных форм миграционной активности занимают суточные горизонтальные и верти- 
кальные миграции, характеризующиеся изменением местообитания гидробионтов и связанные, в большинстве случаев, с суточным циклом [2].

\section{Материал и методы исследований}

Исследовали суточную динамику видового разнообразия и плотности скоплений рыб в прибрежье водохранилища Кам Лам $\left(12^{\circ} 06^{\prime}\right.$ с. ш., $109^{\circ} 04^{\prime}$ в. д.) и одного из его основных притоков - Суои Кок $\left(12^{\circ} 05^{\prime}\right.$ с. ш., $109^{\circ} 04^{\prime}$ в. д.).

Рыб отлавливали пятиметровым бреднем с размером ячеи 6 мм на трех стандартных полигонах площадью $200 \mathrm{~m}^{2}$ на глубине $0-1,5$ м. Лов осуществляли на протяжении 30-45 минут в течение суток с периодичностью 3 часа. Полигон № 1 - защищенное мелководье (залив) с хорошо развитыми зарослями прибрежно-водной растительности. Стоковое течение фактически отсутствует. Преобладают ветровые течения разной скорости и направленности. Полигон № 2 - открытое мелководье без зарослей макрофитов, дно с песчаным грунтом. Полигон № 3 - устьевая зона р. Суои Кок, скорость течения 0,05-0,10 м/с, дно песчано-илистое, отдельные заросли прибрежноводной растительности. Численность рыб рассчитывали на $1 \mathrm{~m}^{2}$ с учетом площади притонений. Наблюдения на полигонах № 1 и 2 проводили 11-12 февраля, на полигоне № $3-12-13$ февраля 2011 года.

При рассмотрении суточной динамики видового разнообразия скоплений рыб в прибрежье анализировали изменение числа видов рыб и перераспределение их долей. Для описания структуры прибрежных группировок рыб использовали следующие показатели: индекс биологического разнообразия (энтропия), основанный на функции Шеннона [6], показатель сложности $(\mathrm{Hm})[1 ; 3]$, индекс относительной организации Ферстера $(R)$ [3]. При определении видовой принадлежности рыб использовали работы Рэйнбоза [7], Коттелата [4; 5] и Серова с соавторами [8; 9].

\section{Результаты и их обсуждение}

В уловах отмечено 14 видов рыб из 8 семейств: сем. Belonidae - Xenentodon cancila (Hamilton, 1822), сем. Channidae - Channa striata (Hamilton, 1822), сем. Chandidae - Parambassis siamensis (Bleeker, 1851), сем. Chichlidae - Oreochromis niloticus (Linnaeus, 1758), ceм. Cyprinidae - Henicorhynchus siamensis (Sauvage, 1881), Osteochilus hasselti (Valenciennes, 1842), O. lini Fowler, 1935, Poropuntius laoensis (Günter, 1868), Puntius brevis (Bleeker, 1850), P. rhombeus Kottelat, 2000, Rasbora paviei Tirant, 1885, сем. Hemiramphidae - Hyporhamphus limbatus (Valenciennes, 1846), сем. Notopteridae - Notopterus notopterus (Pallas, 1769), сем. Siluridae-Ompok bimaculatus (Bloch, 1794).

Наиболее высокая частота встречаемости в проведенных обловах в разных прибрежных биотопах обнаружена у особей Rasbora paviei (50-100 \%), Puntius brevis (50$75 \%$ ), Oreochromis niloticus (75-88 \%), Parambassis siamensis (50 \%). Особи Puntius rhombeus отмечены только в устьевой зоне притока (38 \%). В открытом прибрежье водохранилища (преимущественно в составе ночных уловов) встречался Hyporhamphus limbatus (38 \%). В открытом мелководье водохранилища и в устьевой зоне притока средняя численность рыб в светлое время суток (с 6 до 15 ч при освещенности $>1000$ лк) была ниже, чем в темное время суток (с 18 до 3 ч при освещенности < 1 лк). В защищенной литорали средняя численность рыб в прибрежье была выше в дневные часы (рис. 1). В среднем за сутки более высокая плотность скоплений рыб отмечена в биотопах защищенного мелководья $\left(0,6\right.$ экз. $\left./ \mathrm{M}^{2}\right)$. В биотопах открытой литорали водохранилища и устья притока среднесуточная плотность скоплений рыб была ниже $-0,2$ и 0,3 экз. $/ \mathrm{M}^{2}$, соответственно (см. рис. 1 ). 


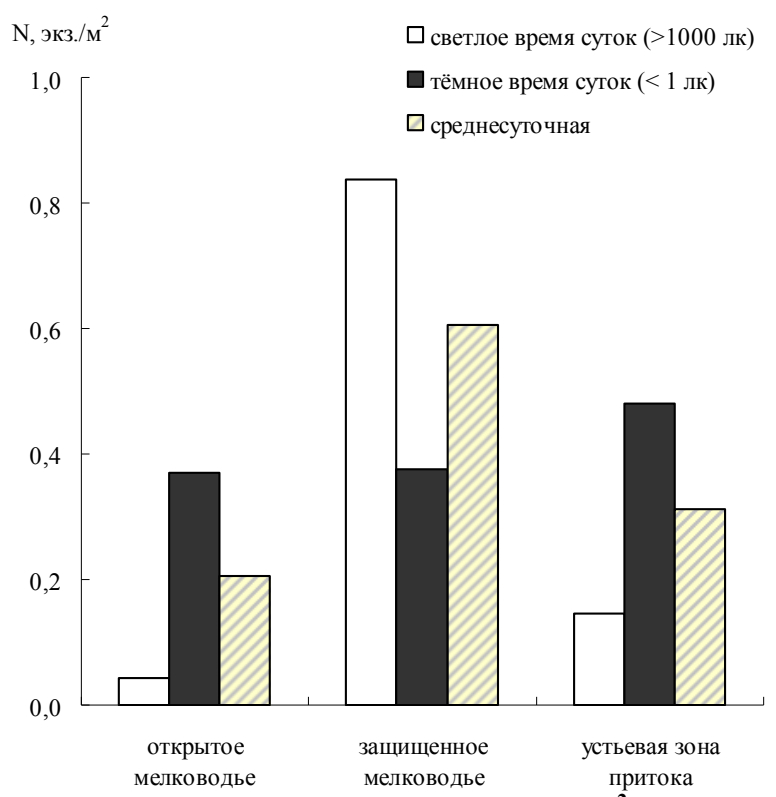

Рис. 1. Плотность прибрежных скоплений рыб $\left(N\right.$, экз./ $\left.\mathbf{M}^{2}\right)$ в различных биотопах водохранилища Кам Лам и р. Суои Кок в разные периоды суток

В открытой литорали водохранилища и в устьевой зоне притока наибольшая плотность прибрежных скоплений рыб $\left(0,4\right.$ и 0,7 экз. $/ \mathrm{m}^{2}$, соответственно) наблюдалась в 18 ч; в защищенном мелководье водохранилища пик численности рыб (2,3 экз./ $\left.\mathrm{M}^{2}\right)$ отмечен в 9 ч утра (рис. 2).

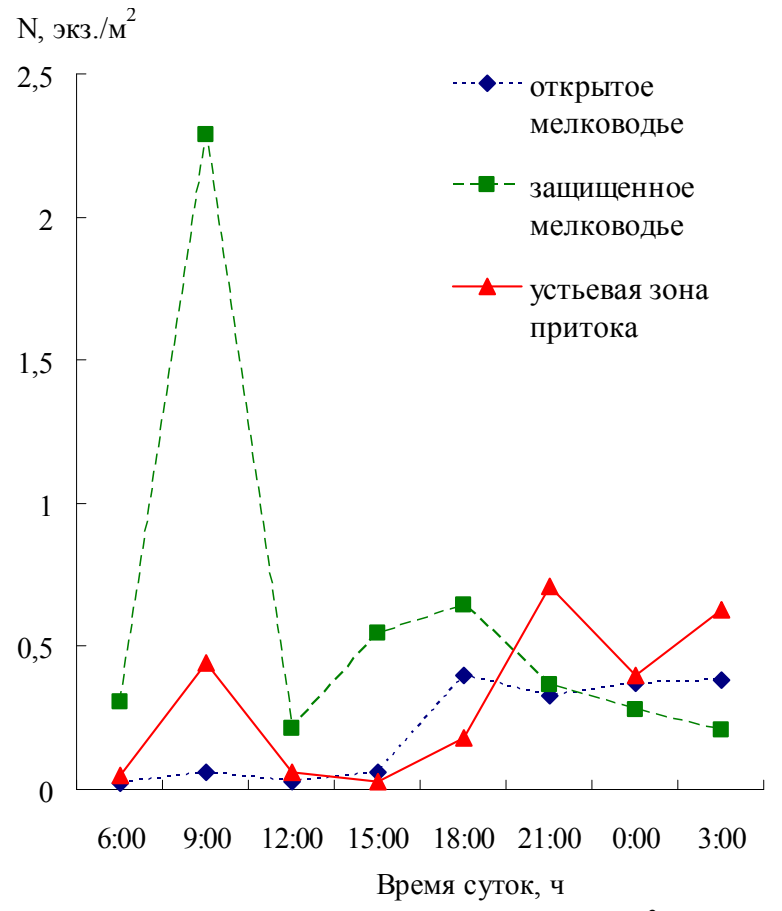

Рис. 2. Суточная динамика общей численности рыб $\left(N\right.$, экз./ $\left.\mathbf{M}^{2}\right)$ в прибрежных биотопах разного типа водохранилища Кам Лам и его притока - р. Суои Кок (февраль, 2011 г.) 
Исследование динамики видового разнообразия прибрежных группировок рыб показало, что в биотопах разного типа на протяжении суток происходило изменение числа видов рыб и перераспределение их долей в составе скоплений. В темное время суток (с 18 до 3 ч) видовое разнообразие прибрежных скоплений рыб возрастало по сравнению со светлым периодом (с 6 до 15 ч) (рис. 3).
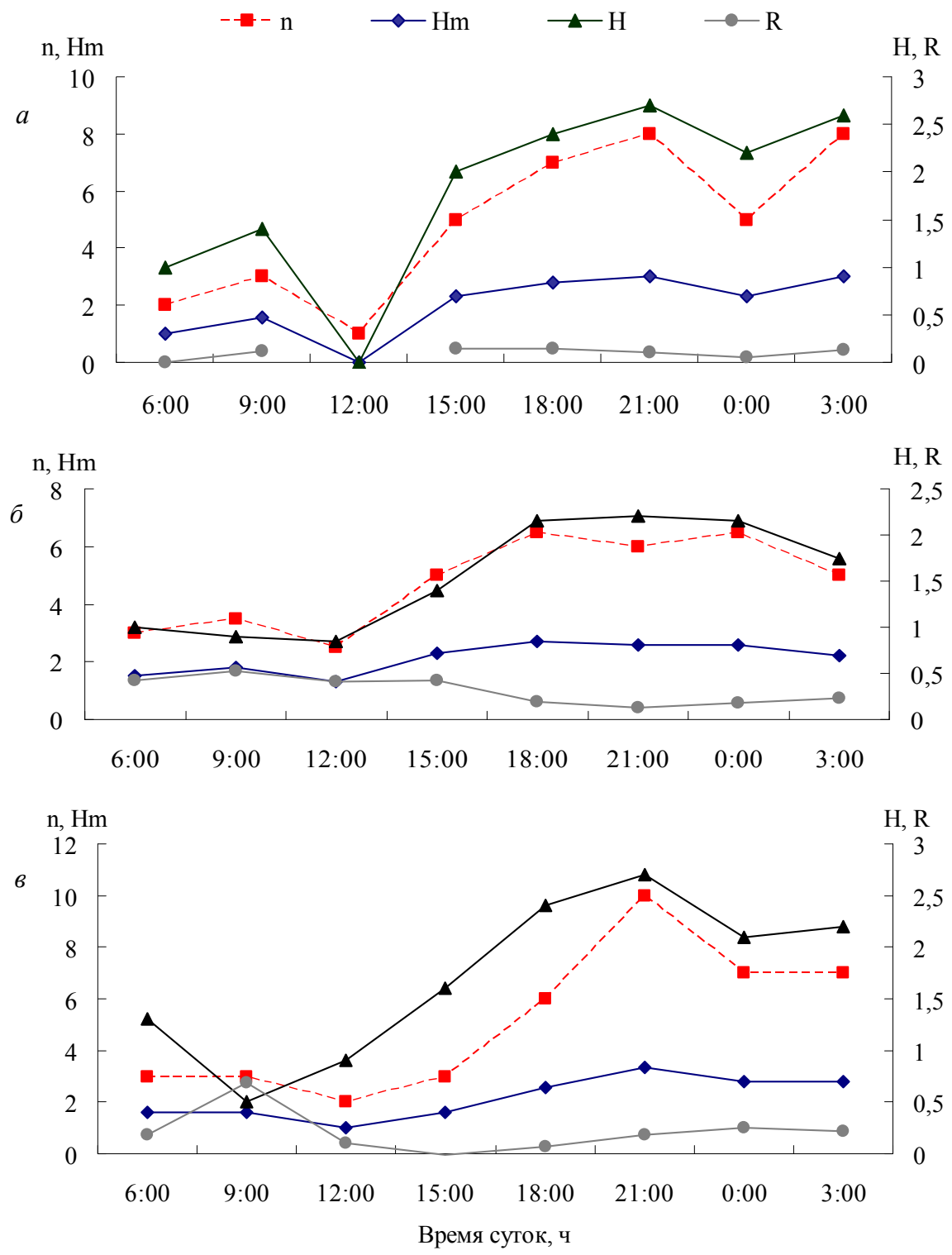

Рис. 3. Суточное изменение структуры прибрежных группировок рыб в открытой $(a)$ и защищенной (б) литорали водохранилища Кам Лам, а также в устьевой зоне р. Суои Кок (в);

$n$ - число видов, $H m$ - показатель сложности, $H$ - индекс биологического разнообразия, $R$ - индекс относительной организации Ферстера

В защищенной литорали водохранилища рост индекса видового разнообразия связан как с увеличением числа видов в составе группировок рыб, так и с уменьшением показателя относительной организации (индекса Ферстера), что свидетельствует о снижении степени доминирования отдельных видов в ночных скоплениях рыб 122 
(см. рис. 3б). В результате этого относительные вклады различных видов рыб в общую численность скопления выравнивались. В составе прибрежных группировок рыб устьевого участка притока наблюдались аналогичные изменения: возрастание показателя видового разнообразия в ночные часы, обусловленное увеличением числа видов и снижением степени доминирования отдельных видов рыб в скоплениях (см. рис. 3в). В группировках рыб открытой литорали водохранилища в темное время суток также происходило увеличение показателя видового разнообразия, однако оно было связано с увеличением числа видов в ночных скоплениях рыб. Уровень доминирования отдельных видов как в дневных, так и в ночных скоплениях рыб был низким и фактически не изменялся (рис. $3 a$ ).

\section{Выводы}

В течение суток плотность скоплений рыб в разных прибрежных биотопах водохранилища Кам Лам и р. Суои Кок изменялась. Пик численности рыб в открытом мелководье отмечен в дневные часы, в защищенной литорали и устьевой зоне притока - в ночное время. В биотопах разного типа на протяжении суток происходило изменение числа видов рыб и перераспределение их долей в составе скоплений. В темное время суток видовое разнообразие прибрежных скоплений рыб возрастало по сравнению со светлым периодом. В защищенной литорали водохранилища и устьевом участке реки рост индекса видового разнообразия обусловлен как увеличением числа видов, так и снижением степени доминирования отдельных видов в ночных скоплениях рыб. В открытой литорали водохранилища возрастание показателя видового разнообразия в ночные часы связано с увеличением числа видов в составе прибрежных группировок рыб.

\section{Библиографические ссылки}

1. Антомонов Ю. Г. Моделирование биологических систем. - К. : Наукова думка, 1977. - 248 с.

2. Павлов Д. С. Механизмы покатной миграции молоди речных рыб / Д. С. Павлов, А. И. Лупандин, В. В. Костин. - М. : Наука, 2007. -213 с.

3. Песенко Ю. А. Принципы и методы количественного анализа в фаунистических исследованиях. - М. : Наука, 1982. - 284 с.

4. Kottelat M. Fishes of Laos. - Sri Lanka : WHT Publications (PTE), 2001. - 198 p.

5. Kottelat M. Freshwater fishes of Northern Vietnam (A preliminary check-list expected to occur in northern Vietnam with comments on systematics and nomenclature). - EASES, 2001. - 123 p.

6. Pielou E. C. Mathematical Ecology. - New York, 1977. - 385 p.

7. Rainboth W. J. Fishes of the Cambodian Mekong. FAO Species Identification Field Guide for Fishery Purposes. - Rome : FAO, 1996. - 265 p.

8. Serov D. V. Fishes of the river Cai / D. V. Serov, V. K. Nezdoliy, D. S. Pavlov. - Moscow : GEOS, 2003. $-164 \mathrm{p}$.

9. Serov D. V. The freshwater fishes of Central Vietnam / D. V. Serov, V. K. Nezdoliy, D. S. Pavlov. M. : KMK Scientific Press Ltd., 2006. - 364 p.

Надійшла до редколегії 08.01.2012 